\title{
DYNAMIC BEHAVIOR OF PANEL RADIATORS - THERMOGRAPHIC INVESTIGATION AND COMPUTER MODELING OF HEAT-UP
}

\author{
Luděk JANČíK, Jiří BAŠTA
}

\begin{abstract}
Research project dealing with dynamic behavior of panel radiators is motivated by current needs for energy savings. Radiators of various types and dimensions were experimentally investigated with thermal imaging; obtained data were used in computer models describing heat-up and cool-down of a radiator. In this article, thermographic observation of fluid flow in a radiator as well as several strategies of heat-up modeling are described and discussed.
\end{abstract}

\section{INTRODUCTION}

Research project dealing with dynamic behavior of panel radiators has been motivated by the overall need for energy savings. Panel radiators are commonly used for heating of buildings in the region of central Europe, therefore a more detailed knowledge of processes during heat-up and cool-down should enable further improvement and optimization of heating systems.

This research project was started in 2007 at the Department of Environmental Engineering, which is a part of the Faculty of Mechanical Engineering at Czech Technical University in Prague. During the research both theoretical (computer modeling and analysis, mainly with Matlab/Simulink) and experimental (thermal imaging) methods were used.

The objectives are proper investigation of physical processes, thus enhancing the knowledge base related to the field of heating technology, as well as creating a simple calculation method describing the transient states of heating panel radiators and finally defining a methodology for infra-red measurement of panel radiators.

This paper is focused on analysis of a fluid flow through a radiator with bottom-bottom opposite end connection as well as on heat-up process modeling strategies.

\section{EXPERIMENT DESCRIPTION}

The experimental facility was described in more detail in previous works (e.g. [1]), crucial components are an infra-red camera ThermaCAM ${ }^{\circledR} \mathrm{S} 65$ and a specially designed heat source with steady output temperature. A measured radiator is attached to an insulated wall, thus eliminating changes of the rear wall temperature and simplifying the analysis process. The measurement takes place in a large open hall laboratory (open space test facility according to [2]); the internal volume is big enough to keep the environmental conditions steady even for a longer operation of the measured radiator.

\footnotetext{
- Ing. Luděk Jančík

Ústav techniky prostředí FS ČVUT, Technická 4, 16607 Praha 6

tel.: +420224352477 e-mail: L.Jancik@fs.cvut.cz
}

This is an Open Access article distributed under the terms of the Creative Commons Attribution License 2.0, which permits unrestricted use, distribution, and reproduction in any medium, provided the original work is properly cited. 


\section{FLUID FLOW OBSERVATION}

Applicability of thermal imaging for fluid flow observation can be documented on following example, obtained during experiments on a special 1-pipe heating system (see Fig. 1), which was originally designed for other purposes. Its advantage is lower material consumption, whereas more complicated control and design can be mentioned as disadvantages, more can be found e.g. in [3].

The first radiator $(11-500 \times 1000)$ was attached to the core pipe with bottom-bottom opposite end (BBOE) connection, while the second one with top-bottom opposite end (TBOE) connection.

The system was pre-heated to approximately $65^{\circ} \mathrm{C}$ with the first radiator closed (left column in Fig. 2). After opening the first radiator, a thermal image sequence was taken, resulting thermograms are presented in Fig. 2. After 3 minutes, a stream of hot water flowing directly from inlet to outlet at the bottom without entering the main heat exchange area of the radiator is clearly visible.

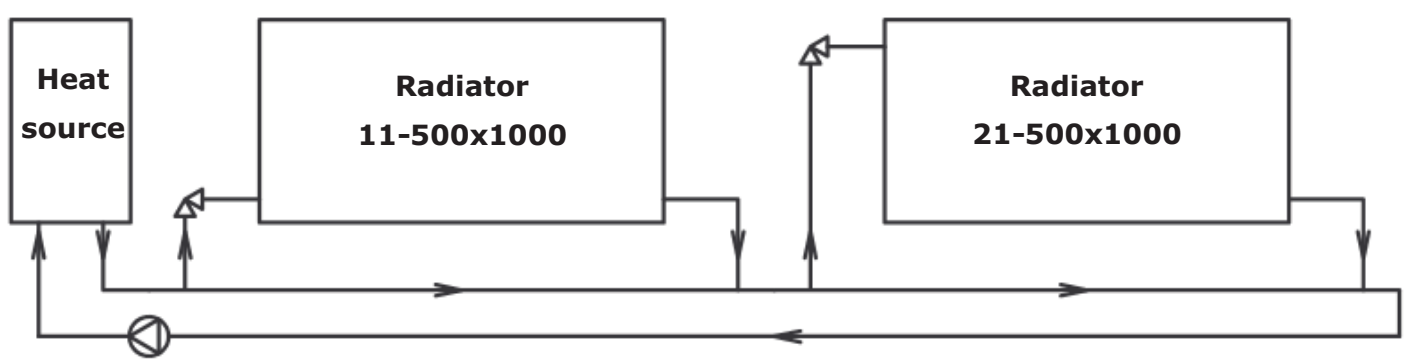

Figure 1 Simplified scheme of a 1-pipe heating system.

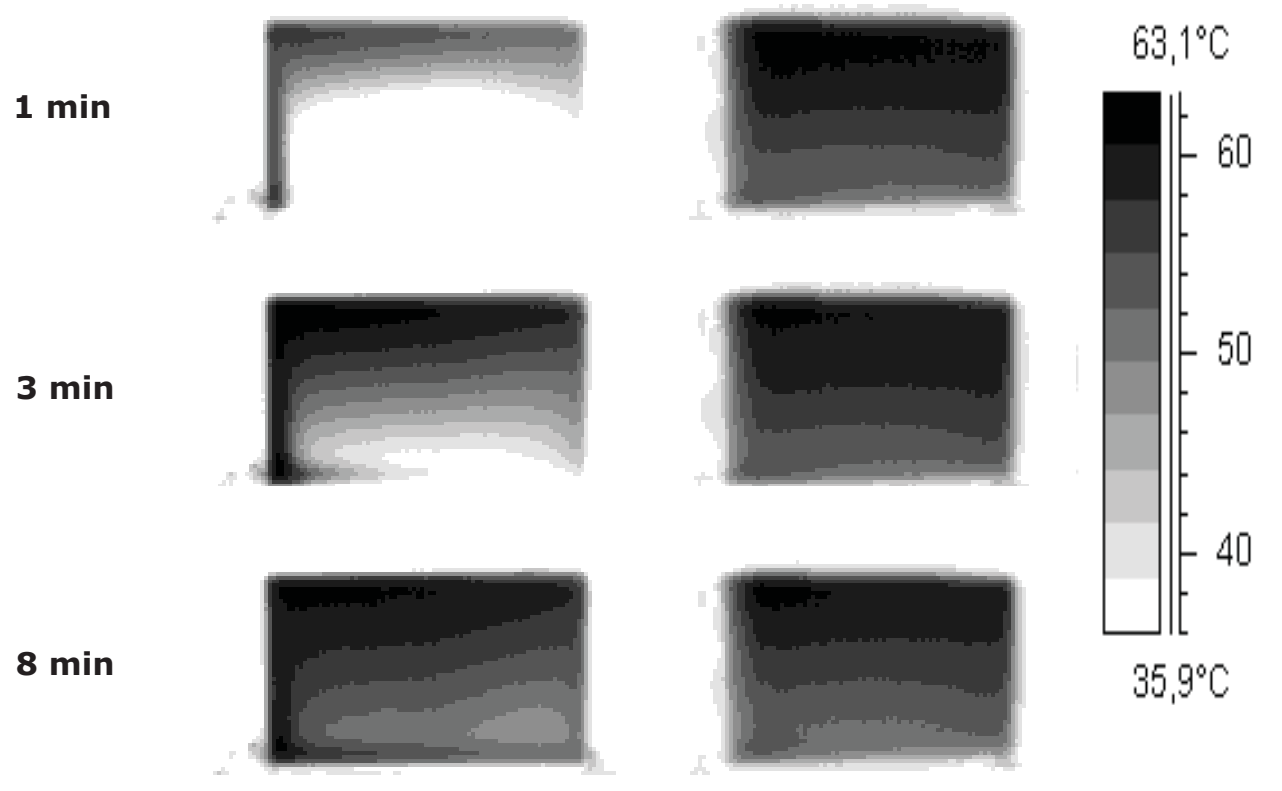

Figure 2 Heat-up process sequence and temperature field pattern of a 11$500 \times 1000$ radiator with BBOE connection (left column) compared to a 21$500 \times 1000$ radiator with TBOE connection (right column) under quasi-steady conditions, radiators connected next to each other to a 1-pipe heating system. 
The second radiator remained opened for the whole time, because the original intention of this experiment was observation of mutual influence of radiators within a 1-pipe heating system. For this purpose, a slight decrease of heating output can be derived from the changed temperature field pattern, which was shifted towards lower temperatures.

\section{HEAT-UP PROCESS MODELING}

First attempts of creating a model of a radiator in this research project were performed for cool-down process, which is generally simpler due to missing fluid flow. These models, derived from the overall energy balance equation (1) and computed in Matlab/Simulink environment, were described in [4] and proved feasibility of this approach, showing a very good agreement with experimental data (relative deviation about $4 \%$ ).

$\frac{d t_{m}}{d \tau}=\frac{1}{\left(m_{T} \cdot c_{T}+m_{W} \cdot c_{W}\right)} \cdot\left[\dot{m}_{W} \cdot c_{W} \cdot\left(t_{\text {in }}-t_{\text {out }}\right)-\alpha_{C} \cdot S_{T} \cdot\left(t_{m}-t_{O}\right)\right]$

Nevertheless for a heat-up process, this approach based on overall energy balance did not lead to good results - with relative deviation about $30 \%$ from experimental data. This was caused by the fact, that during the first phase of heat-up, when the radiator is being filled with hot water, almost all components of the energy balance equation (1) become variable (2). Heat exchange area and heated radiator mass can be estimated according to known mass flow of heating water, but determination of the outlet water temperature (and thus the amount of heat energy transferred into the system) in the period between the opening of valves and the first change indicated by the outlet thermometer constitutes a real problem.

$\frac{d t_{m}}{d \tau}=\frac{1}{\left(m_{T}(\tau) \cdot c_{T}+m_{W}(\tau) \cdot c_{W}\right)} \cdot\left[\dot{m}_{W} \cdot c_{W} \cdot\left(t_{\text {in }}-t_{\text {out }}(\tau)\right)-\alpha_{C}(\tau) \cdot S_{T}(\tau) \cdot\left(t_{m}(\tau)-t_{O}\right)\right]$

A possible solution based on transfer functions and experimentally obtained time constant was presented in [5] and the results were in a good agreement with experiments (relative deviation about $5 \%$ ). On the other hand, calculation of transfer functions needs either a specialized software (Matlab/Simulink in this case) or Laplace transformation and analytical solution for further use, also time constants relevant for particular radiator must be known, therefore the search for another and simpler method continued.

At first, using the advantages of Matlab/Simulink environment, all variables in the equation (2) were programmed into subsystems taking into account assumption (3), which simplify the solution by eliminating the variable and unknown (during the first "filling" phase of heat-up) outlet water temperature, and also (4) and (5), that explain the use of the overall heat transfer coefficient both for convection and radiation. Despite that, the results did not match the experimental data - relative deviation is still about $30 \%$ (see Fig. 3, curve marked as "Simulation 1").

$t_{m}=\frac{t_{\text {in }}+t_{\text {out }}}{2}$ 
$\alpha_{c}=\alpha_{K}+\alpha_{S}$

$\alpha_{S}=\varphi \cdot \varepsilon \cdot \sigma \cdot \frac{\left(T_{m}^{4}-T_{i}^{4}\right)}{t_{m}-t_{i}}$

As can be also seen in Fig. 3, the upper part of the resulting curve seems to be similar as the upper part of the curve constructed from experimental data. This finding inspired another approach based on the energy balance equation - the modeling process started at the time when the radiator should be full of the pre-heated water (according to the known mass flow and internal volume) and all coefficients in the equation were taken as constant (6) with the initial value of mean radiator temperature $t_{m}=47^{\circ} \mathrm{C}$, which is an arithmetic average of ambient air temperature $t_{i}=19^{\circ} \mathrm{C}$ and inlet water temperature $t_{\text {in }}=75^{\circ} \mathrm{C}$. The results ("Simulation 2 " in Fig. 3 ) were surprisingly good, with a relative deviation of about $5 \%$ for the simulated upper part of the curve. The lower part of the curve was approximated with a line starting at ambient air temperature at time delay determined from experimental data $(70 \mathrm{~s})$, deviation from experimental data is then up to $10 \%$.

Unfortunately, for other studied cases this approach did not work good enough, the assumption for the initial value of mean radiator temperature mentioned above is not valid for different ambient air temperatures and radiator dimensions, resulting deviations exceeded $10 \%$.

For another comparison, a curve constructed again from the equation (6) but starting from the ambient air temperature is shown in Fig. 3 ("Simulation 3").

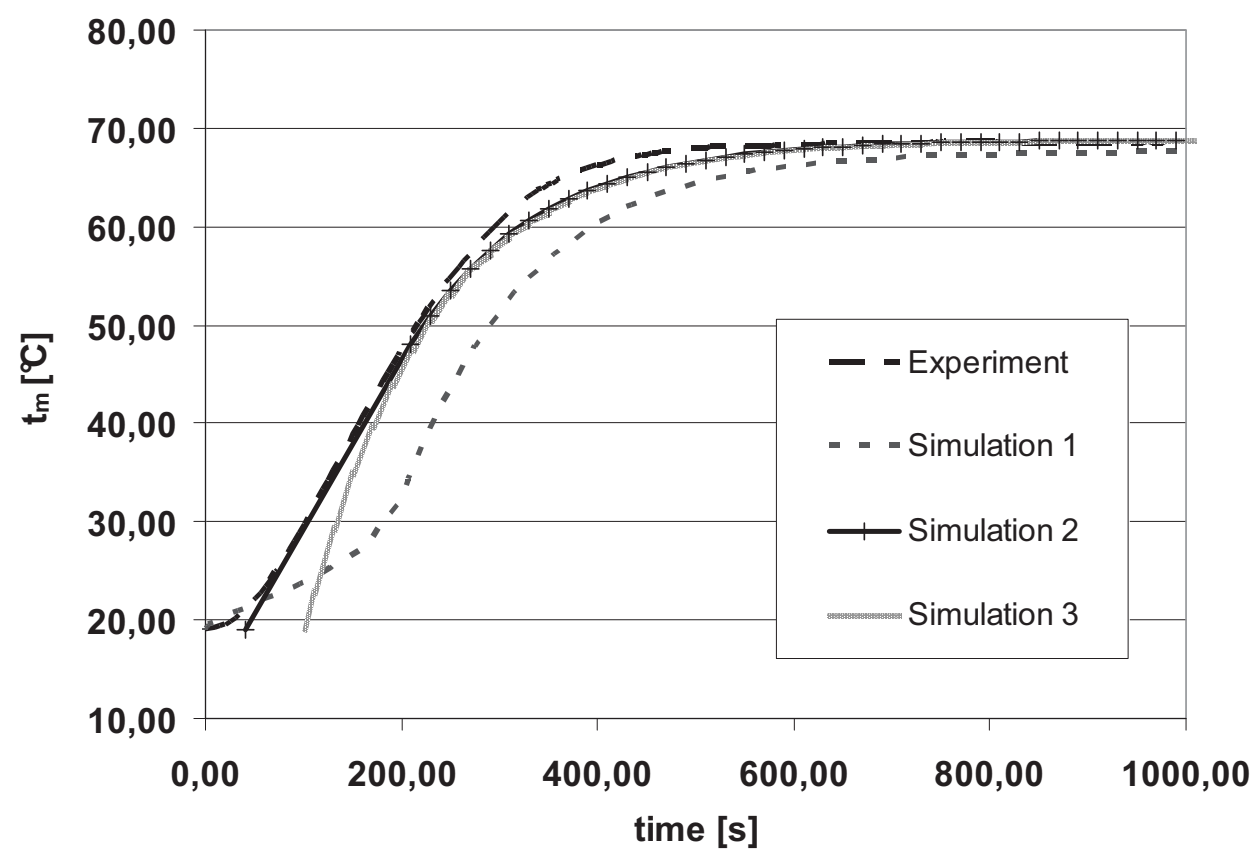

Figure 3 Results of heat-up process simulation for a radiator $10-500 \times 1000$ compared to experimental data. Simulation $1=$ energy balance equation with variable coefficients (2) Simulation 2 and $3=$ energy balance equation with constant coefficients shifted to the "fill-up" time of the radiator (6), further explanation in previous paragraph. 


$$
\frac{d t_{m}}{d \tau}=\frac{1}{\left(m_{T} \cdot c_{T}+m_{W} \cdot c_{W}\right)} \cdot\left[2 \cdot \dot{m}_{W} \cdot c_{W} \cdot\left(t_{i n}-t_{m}\right)-\alpha_{C} \cdot S_{T} \cdot\left(t_{m}-t_{O}\right)\right]
$$

\section{Discussion}

As can be seen in Fig. 2, analysis of thermograms can be used even for secondary fluid flow observation. In the described case, a visible stream of heating water which flows directly from inlet to outlet of the radiator indicates lower efficiency of BBOE (bottombottom opposite end) type of radiator connection. Although this is a known fact (e.g. in [3]), the visualization shown above can serve as an explanation and a base for additional analysis.

Furthermore, the change in the thermal field pattern on the second radiator shows the consequences of mutual influence of radiators connected to a 1-pipe heating system. The shift towards lower temperatures is apparent, the result is a slightly lower heating output of the second radiator, which is again a known fact, but for this time it was observed during a real-time measurement and in the whole area of a radiator.

Bad results of a complex heat-up model (with variable coefficients, "Simulation 1" in Fig. 3) could mean that during the initial phase of heat-up, heat conduction acts such an important role that the whole process can not be described exactly just with the energy balance equation (2). But the incorporation of heat conduction means solving a second order partial differential equation, therefore the approach based on relatively simple energy balance equation was not cancelled.

Rather good approximation of the upper part of the heat-up curve with energy balance model is another explanation for its use. Even though no general rule for positioning the initial mean radiator temperature has been found yet, this approach should be possible, because relevant time constants are known from experimental measurements. Thus the value of time delay is known and an approximation line of the quasi-linear phase of heatup could be constructed (see Fig. 3). Although it requires the use of experimental data for each radiator type, the resulting method should be theoretically simpler since it does not need the transfer functions (described e.g. in [5]). But of course, it means further validation for studied radiator types and temperature ranges.

\section{CONCLUSION}

Benefits of thermal imaging for fluid flow observation were demonstrated for radiators connected to a 1-pipe heating system (Fig. 1). A direct stream of heating water between radiator inlet and outlet, which should explain a lower efficiency of bottom-bottom opposite end radiator connection, was identified on experimental thermogram presented in Fig. 2.

Modeling of heat-up using a simplified approach based on energy balance equation (6) is promising due to a good approximation of the upper part of heat-up curve (Fig. 3) but measured time constants are needed for correct positioning of initial set point and thus an additional validation for various types of radiators and temperature ranges is necessary. 


\section{NOMENCLATURE}

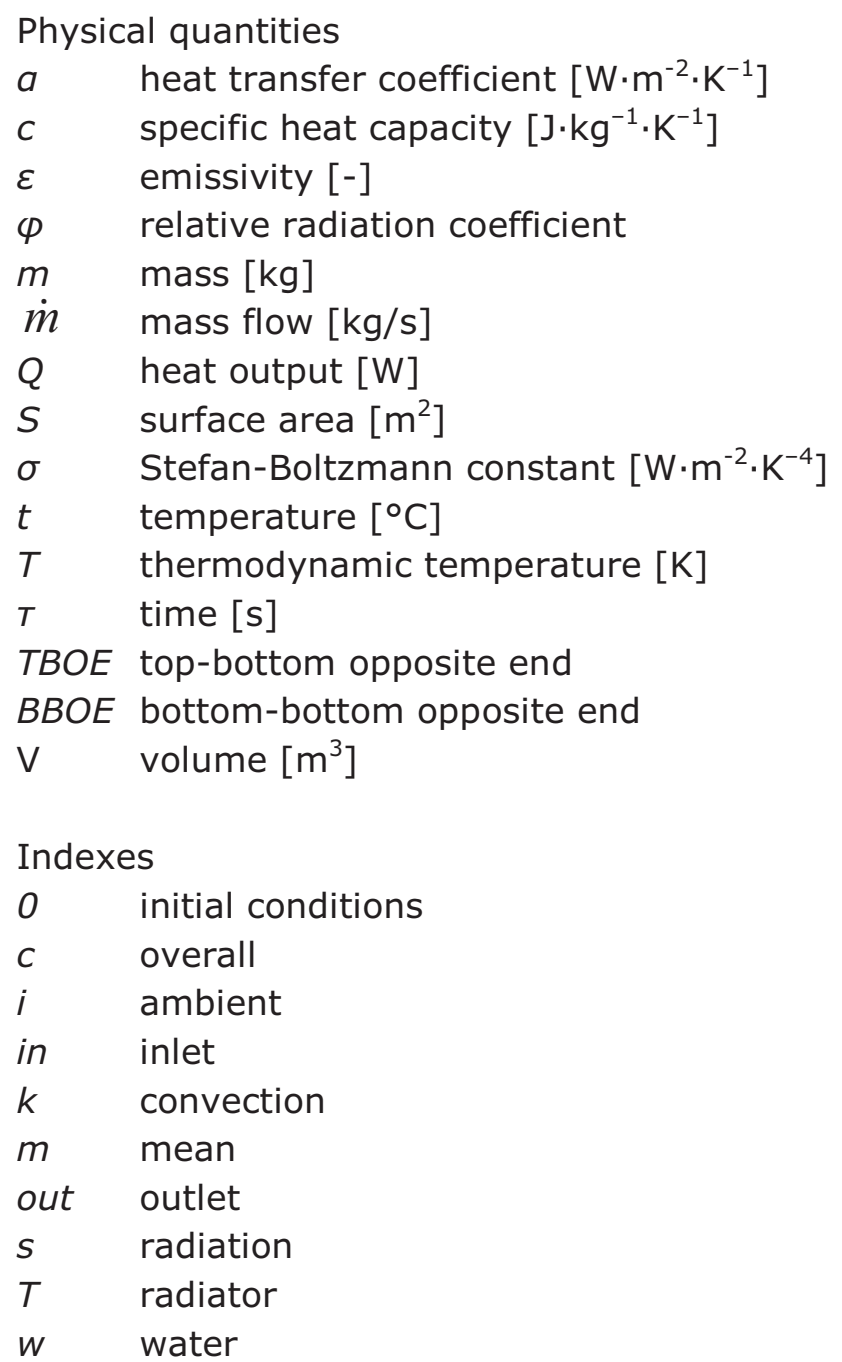

\section{REFERENCES}

[1] Jancik L., Basta J.: Thermographic Measurement of Dynamic Behaviour of Panel Radiators, Proceedings of Experimental Fluid Mechanics 2008, TU Liberec, 2008, p. 61 - 71 ISBN 978-80-7372-417-7

[2] CSN EN 442-2:1996 Radiators and Convectors - Part 2: Test Methods and Rating.

[3] Bašta, J.: Heating Surfaces. In Czech: Otopné plochy. Prague: 2001. 328 p. ISBN 80-01-02365-6.

[4] Jančík L., Bašta J. Posouzení dynamického chování otopných těles termografickou metodou. Konference simulace budov a techniky prostředí, Brno, 2008, 4 s.

[5] Jancik L., Basta J.: Dynamic Behaviour of Panel Radiators - Further Investigation, Proceedings of Experimental Fluid Mechanics 2009, TU Liberec, 2009. p. 83 - 91 ISBN 978-80-7372-538-9 